\title{
SURFACE AND DEEP WATER CIRCULATION IN LATE CRETACEOUS NORTH ATLANTIC GREENHOUSE OCEAN
}

\section{Carolina Isaza Londoño}

\section{Dr. Kenneth G. MacLeod, Dissertation advisor}

\begin{abstract}
Knowledge of past climates can provide important lessons about current and future climate evolution. Knowledge of climate evolution is a particularly pressing issue in light of the current debate about climatic change in our immediate future. The Intergovernmental Panel on Climate Change (IPCC, 2008) recognized that global warming could have a dramatic effect on thermohaline circulation, and, as we move towards a new greenhouse word, it is important to understand how ocean circulation might respond to this warming. For the immediate future, studying warm intervals in the geologic past is especially important as these times provide the only empirical record of ocean circulation during greenhouse conditions. Among past warm climates, the Cretaceous is an excellent interval to study; it is widely agreed to be a time of high atmospheric $\mathrm{CO}_{2}$ levels and warm temperatures with an accessible and well preserved record.

Divergent temperature trends among ocean basins are observed during the Maastrichtian, the last 7 million years of the Cretaceous. Results from this research (foraminiferal abundances, neodymium isotopes of fish debris, and oxygen and carbon isotopic ratios of bulk carbonate and foraminifera) indicate that the Maastrichtian was a transitional time where low latitude sources of deep water switched off and high latitude downwelling may have intensified. That is, our data demonstrate that surface and
\end{abstract}


especially intermediate and deep water circulation patterns are an important (and measurable) variable that help determine greenhouse temperature distributions on regional and global scales. This finding is important for current environmental discussions because, as a consequence of global warming, IPCC $\mathrm{pCO}_{2}$ estimates for 2100 are similar to those observed in the Maastrichtian, raising the possibility that the scale of changes seen during the Maastrichtian (switch from high latitude to low latitude sources of deep water with consequent changes in climate and ocean/land ecosystems) are possible in the near future. 